\title{
A MULTIMODALIDADE COMO FERRAMENTA \\ DE INCLUSÃO NO JORNALISMO CIENTÍFICO
}

\section{Multimodality as a Tool of Inclusion in Scientific Journalism}

DOI: 10.14393/LL63-v36n1-2020-10

Luana Macieira Barbosa*

RESUMO: Este artigo tem por objetivo refletir sobre o modo como a multimodalidade se faz presente no discurso de jornalismo científico. Nos debruçamos sobre matérias da revista Pesquisa FAPESP, publicação jornalística impressa dedicada à divulgação de pesquisas científicas. Uma vez que as páginas de uma revista são compostas por notícias formadas por textos, imagens, gráficos e fotos, utilizamos textos jornalísticos para observar como o fenômeno da multimodalidade ocorre. Neste trabalho, consideramos as relações entre poder e discurso de Gnerre (2009) e Fairclough (2001), além das categorias de análise elaboradas por Kress e van Leeuwen (2006) em Reading images. The grammar of visual design. Nossos resultados apontam para o fato de que, no atual cenário de crise democrática, o jornalismo científico utiliza recursos multimodais para tornar os textos mais inteligíveis, funcionando como ferramenta de inclusão e auxiliando para que o discurso da ciência não seja usado como elemento de poder por aqueles que o produzem nos laboratórios, institutos de pesquisa e universidades.

PALAVRAS-CHAVE: Multimodalidade. Jornalismo científico. Divulgação científica. Discurso. Poder.

ABSTRACT: This article aims to reflect upon how multimodality is present in the scientific journalism discourse. It analyses the journalistic articles published in Pesquisa FAPESP, a print magazine devoted to disseminate scientific research. As the pages of a magazine consist of texts, images, graphics and photos, the articles were used to observe how multimodality occurs in this kind of text. The analysis draws on the relationships between power and discourse as posited by Gnerre (2009) and Fairclough (2001), as well as the categories of analysis proposed by Kress and van Leeuwen (2006) in Reading images. The grammar of visual design. The results show that, in the current context of democratic crisis, scientific journalism uses multimodal resources to make texts more intelligible, serving as a tool of inclusion and preventing the discourse of science from being used as an element of power by those who produce it inside laboratories, research institutes, and universities.

KEYWORDS: Multimodality. Scientific journalism. Popular science. Discourse. Power.

* Doutoranda em Linguística Aplicada no Instituto de Estudos da Linguagem da Universidade Estadual de Campinas (UNICAMP). ORCID: 0000-0003-0360-9084. E-mail: macieira.luana(AT)gmail.com. 


\section{Introdução}

Vivemos um período político no Brasil caracterizado por uma reconfiguração política e social, pelo crescimento do autoritarismo e por constantes ataques sofridos pela ciência. A todo momento vemos, em textos publicados na internet e em redes sociais, questionamentos sobre a importância e a veracidade das descobertas científicas em diversas áreas do conhecimento. Apesar de estarmos no século XXI, somos bombardeados por questionamentos que variam desde a esfericidade da terra até a existência do aquecimento global, fenômenos que, até então, já haviam sido comprovados por experimentos científicos realizados em várias partes do mundo.

Junto aos constantes ataques sofridos pela ciência no país, somam-se os cortes orçamentários que o atual governo tem feito às pastas da ciência e da educação. No primeiro semestre de 2019, o atual presidente anunciou cortes de $\mathrm{R} \$ 819$ milhões, além do congelamento de bolsas de pesquisa e do contingenciamento de $30 \%$ das verbas de custeio e investimentos das universidades públicas federais, principais realizadoras de pesquisas científicas no país. ${ }^{1}$

O ataque à ciência e a falta de estímulo governamental para a continuidade das pesquisas científicas no Brasil corrobora a importância do jornalismo científico no país. Oliveira (2002) afirma que este tipo de jornalismo se dedica à divulgação de textos relacionados às descobertas e avanços que ocorrem nas diversas áreas do conhecimento, como biologia, medicina, engenharia, física, química, filosofia e artes, sendo uma das principais maneiras pelas quais os cidadãos brasileiros se mantêm informados sobre os estudos que são realizados nas universidades e institutos de pesquisa. Segundo a autora (2002), a sociedade está cada vez mais interessada em obter informações sobre ciência e tecnologia (C\&T) e o conhecimento de assuntos relacionados a esses temas é essencial para o exercício da cidadania, quando a população passa a interferir nas decisões políticas ligadas às transformações realizadas pelas pesquisas de C\&T, uma vez que uma comunidade bem informada tem mais autonomia para opinar e julgar políticas e ações governamentais na esfera tecnológica.

\footnotetext{
${ }^{1}$ O valores foram catalogados pela Associação Brasileira para o Progresso da Ciência (SBPC).
} 
Concordamos com Oliveira (2002) quando esta destaca a importância que o jornalismo científico possui em nossa sociedade e acreditamos que, ao mesmo tempo em que os resultados do avanço científico e tecnológico podem parecer distantes da vida cotidiana das pessoas, é importante que a sociedade tenha acesso a esse tipo de informação. Halliday (2004) afirma que o discurso sobre ciência não pode ser visto como um privilégio da elite, pois o acesso inteligível a esse tipo de discurso é essencial para a produção de conhecimento e para o aprendizado das pessoas. Halliday e Martin (1996) destacam que a ciência deve ser vista como uma prática linguístico-semiótica que "pode ser desconstruída e acessível, como parte de uma agenda maior, que linguisticamente constrói um mundo que é reconhecido por todos que vivem nele" (HALLIDAY; MARTIN, 1996, p. xi, tradução nossa²). Os autores veem, então, o discurso da ciência como uma importante ferramenta política e pedagógica, pois "a maneira como a ciência é escrita e lida, falada e escutada, está obrigatoriamente relacionada a questões de acesso, educação e letramento literário" (HALLIDAY; MARTIN, 1996, p. xiv, tradução nossa ${ }^{3}$ ). Dessa forma, o jornalismo científico contaria com relações de poder que permeariam as relações sociais dos sujeitos envolvidos na produção deste tipo de jornalismo.

Segundo Oliveira (2002), a formação de uma cultura científica que torne as pessoas interessadas em temas deste campo leva tempo, mas o acesso às informações de ciência e tecnologia facilita esse processo. Assim, acreditamos que o jornalismo científico, no atual cenário de crise democrática, é uma importante ferramenta de inclusão, auxiliando para que o discurso da ciência não seja usado como elemento de poder pela privilegiada parcela da população que tem acesso a ele.

\section{0 discurso científico e o poder}

O jornalismo científico é visto por Bueno (1985) como uma ferramenta de divulgação do progresso científico e tecnológico, além de ter funções informativa, educativa, social e cultural. Segundo o pesquisador (BUENO, 1985), a função informativa deste tipo de

\footnotetext{
${ }^{2}$ No original: “(...) can be deconstructed and made accessible, as part of a broad agenda to linguistically construe a world which is recognizable to all those who live in it." (HALLIDAY; MARTIN, 1996, p. xi)

${ }^{3}$ No original: "How science is written and read, spoken and heard is necessarily tied up with questions of access, education and critical literacy." (HALLIDAY; MARTIN, 1996, p. xiv)
} 
jornalismo é divulgar fatos de relevância para a sociedade. A função educativa pressupõe uma intenção pedagógica, que é exercida quando o jornalismo científico explica ciência aos seus leitores. A função social pode ser observada quando o jornalismo científico se preocupa em situar a informação sobre ciências no contexto em que o leitor está inserido, ou seja, o jornalista se preocupa em aproximar o conhecimento científico da vida do leitor. Já a função cultural tem ligação com a dominação cultural que pode ser exercida por esse tipo de jornalismo, uma vez que a posse do conhecimento pode servir como objeto de manipulação (BUENO, 1985, p. 1424-1426).

Bueno (1985) também destaca a existência de funções econômica e políticoideológica no jornalismo científico. A função econômica refere-se à relação existente entre o conhecimento que é divulgado e suas consequências para o setor produtivo e a economia de uma comunidade, enquanto a função político-ideológica faz referência à importância dessa modalidade jornalística para a não-alienação do povo e sua participação nas políticas governamentais de C\&T.

Quando falamos do uso da linguagem do jornalismo científico como elemento de poder, recorremos a Gnerre (2009) e a Fairclough (2001). Para Gnerre, as produções linguísticas adquirem valor quando realizadas nos contextos social e cultural apropriados, uma vez que "as regras que governam a produção apropriada dos atos de linguagem levam em conta as relações sociais entre o falante e o ouvinte" (GNERRE, 2009, p. 6). Ao destacar que a linguagem pode ser usada para impedir a comunicação de certos tipos de informação para grandes setores da população, o autor cita a linguagem e os jargões utilizados em documentos jurídicos como barreira para que estes documentos não sejam acessíveis à maior parte da sociedade. Aqui, achamos interessante realizarmos um paralelo com o que ocorre na linguagem científica, que também tem poder de exclusão, uma vez que

(...) a função central de todas as linguagens especiais é social: elas têm um real valor comunicativo mas excluem da comunicação as pessoas da comunidade linguística externa ao grupo que usa a linguagem especial e, por outro lado, têm a função de reafirmar a identidade dos integrantes do grupo reduzido que têm acesso à linguagem especial. (GNERRE, 2009, p. 23)

A visão de Fairclough (2001) sobre a relação entre linguagem e poder parte do pressuposto de que a primeira pode produzir, manter ou mudar as relações sociais de poder, 
além de materializar e mostrar o lugar dos sujeitos nessas relações. Para o autor, entender que a linguagem contribui para que algumas pessoas exerçam domínio sobre outras é o primeiro passo para a emancipação dos povos que são dominados. No caso deste artigo, vemos relações de poder que atuam nas esferas sociais do pesquisador/cientista, do jornalista e do público/leitor da matéria jornalística.

Em se tratando da mídia e do jornalismo, tal percepção é importante porque, segundo Fairclough (2001), o discurso dos meios de comunicação (e aqui enquadramos a prática do jornalismo científico) conta com relações de poder que nem sempre são claras e que podem estar escondidas nas relações sociais. O autor afirma que a mídia é, então, capaz de exercer poder de diversas maneiras. "Podemos dizer que os produtores exercem poder sobre consumidores na medida em que eles possuem direitos exclusivos de produção e podem, portanto, determinar o que está incluído e excluído, como os eventos são representados e até mesmo a posição dos sujeitos de suas audiências" (FAIRCLOUGH, 2001, p. 42, tradução nossa ${ }^{4}$ ).

Assim, a atuação do jornalista como intermediador entre o pesquisador e o leitor é importante para que o cidadão comum não seja excluído totalmente do ambiente no qual uma pesquisa científica é realizada. Fairclough (2001) exemplifica o uso da linguagem como elemento de exclusão citando a relação existente entre médico e paciente, quando a linguagem usada pelos dois demarca a hierarquia social entre os sujeitos. Aqui, podemos fazer um paralelo com o jornalismo científico: a relação entre pesquisador/cientista e leitor também é desigualmente hierárquica, visto que aquele detém um saber e um discurso que este último desconhece. Segundo preceitos que regem a produção jornalística, o discurso científico, permeado de jargões e composto por um vocabulário técnico e inacessível às pessoas não-iniciadas no tema, é transformado pelo jornalista para que se torne mais acessível a um público que não faz parte da comunidade científica. Por meio desse paralelo, podemos dizer que os cientistas fazem uso de uma linguagem que exclui parte da sociedade

\footnotetext{
${ }^{4}$ No original: "We can say that producers exercise power over consumers in that they have sole producing rights and can therefore determine what is included and excluded, how events are represented, and even the subject positions of their audiences." (FAIRCLOUGH, 2001, p. 42)
} 
das descobertas científicas, enquanto o jornalista especializado em ciência teria, como função principal, traduzir o discurso desse pesquisador, quebrando essa hierarquia.

Em se tratando da exclusão que ocorre em certos domínios do conhecimento e que pode ser corroborada pela linguagem, Fairclough afirma que

Um aspecto do poder é a sua capacidade de impor e manter uma estrutura particular de algum domínio ou de outro - um jeito particular de dividi-lo em partes, de manter essas partes demarcadas umas das outras, e um pedido particular dessas partes em termos de relações hierárquicas de dominação e subordinação. (FAIRCLOUGH, 2001, p. 10-11, tradução nossa) ${ }^{5}$

A linguagem, vista pelo autor (2001) como uma forma de prática social, precisa ser entendida como elemento transformador dos sujeitos e de suas ações. Essas transformações ocorreriam por meio das convenções, ou seja, pelo uso frequente de certas práticas discursivas. O poder dos pesquisadores (ao escreverem artigos científicos) e dos jornalistas (ao escreverem matérias jornalísticas) advém do fato de que essas duas instâncias sociais são capazes de controlar o discurso científico. Em outras palavras, "o poder nesses níveis inclui a capacidade de controlar as ordens do discurso; um aspecto desse controle é ideológico - garantindo que cada ordem do discurso é ideologicamente harmonizada internamente ou (no nível social) com as outras" (FAIRCLOUGH, 2001, p. 25, tradução nossa6). Ao abordar o controle das ordens do discurso, Faiclough (2001) nos remete ao conceito elaborado por Michel Foucault (1996), para quem os discursos são como redes de signos que se conectam a outros discursos ou a outras redes de discursos, em um sistema aberto que estabelece, reproduz e perpetua os valores da sociedade.

Uma vez que as relações de poder, conforme afirma Fairclough (2001), não estão restritas às classes sociais - podendo ocorrer entre homens e mulheres, grupos étnicos

\footnotetext{
${ }^{5}$ No original: "One aspect of power is the capacity to impose and maintain a particular structuring of some domain or other - a particular way of dividing it into parts, of keeping the parts demarcated from each other, and a particular ordering of those parts in terms of hierarchical relations of domination and subordination." (FAIRCLOUGH, 2001, p. 10-11)

${ }^{6}$ No original: "Power at these levels includes the capacity to control orders of discourse; one aspect of such control is ideological - ensuring that orders of discourse are ideologically harmonized internally or (at the social level) with each other." (FAIRCLOUGH, 2001, p. 25)
} 
diferentes, entre cientistas e jornalistas e, posteriormente, entre jornalistas e leitores, no caso do jornalismo científico - , ressaltamos a importância de estudos no campo da Linguística Aplicada que utilizem, como objeto de análise, produtos do jornalismo científico, visto que este tem importante função social ao ser capaz de fazer com que o conhecimento sobre ciência não fique restrito apenas à comunidade acadêmica e, como consequência, não seja utilizado por essa comunidade como elemento de poder e exclusão.

O jornalismo científico, descrito por Bertolli Filho (2006) como "um produto elaborado a partir de certas regras rotineiras do jornalismo em geral, que trata de temas complexos de ciência e tecnologia e que se apresenta, no plano linguístico, por uma operação que torna fluida a leitura e o entendimento do texto noticioso por parte de um público não especializado" (BERTOLLI FILHO, 2006, p. 3), se torna, então, um dos responsáveis por fazer o conhecimento ultrapassar os muros da comunidade científica, podendo servir como objeto de produção de significado e conhecimento por pessoas que não integram os grupos detentores do discurso e do saber científicos.

\section{A multimodalidade}

Partimos do princípio de que todo texto é planejado em diversas camadas modais (texto, imagem, gráficos, diagramação etc) e que a maneira como os diversos modos semióticos se apresentam para o leitor é resultado de escolhas feitas pelo produtor do texto, que transita entre esses modos de acordo com os objetivos que pretende alcançar.

A ideia de que todo texto já nasce multimodal surgiu com Kress e van Leeuwen (1998). Apesar de aceitarem o fato de que a maioria dos discursos que querem ser vistos como sérios ainda insistirem na monomodalidade, os autores acreditam que a multimodalidade precisa ser reconhecida como inerente aos textos. Para Kress e van Leeuwen (1998), textos comuns com os quais as pessoas têm contato no dia a dia, como jornais, panfletos e livros didáticos, não são apenas escritos, mas articulados de forma multimodal. Às diversas formas de representação, os autores chamam de "modos semióticos".

Todos os textos são multimodais. A linguagem sempre é pensada e acontece na companhia de outros modos semióticos... [...] Quando nós escrevemos, nossa mensagem é expressa não só linguisticamente, mas também por meio de um arranjo visual de marcas na página. Qualquer tipo de análise textual 
que ignora isso não será capaz de contar com todos os significados expressos nos textos. (KRESS; VAN LEEUWEN, 1998, p.186) ${ }^{7}$

Consideramos o texto multimodal como um enunciado concreto e que articula, com o mesmo grau de importância, o texto escrito e o texto imagético. Trata-se do texto cujo significado se realiza por mais de um código semiótico. Esta visão multimodal está inserida em uma perspectiva da semiótica social que referencia o processo de significação do discurso, envolvendo a construção social da linguagem e levando em conta as origens dos significados, os contextos da troca comunicativa e os efeitos de sentido cultural e historicamente construídos.

Para a Semiótica Social, todos os signos devem ser considerados quando se atribui significado a um texto, uma vez que a comunicação ocorre dentro de um contexto social. A língua, além de representar as práticas sociais, influencia e transforma a realidade das pessoas. Por meio dessas definições, a semiótica social passa a servir como ferramenta no processo de leitura visual, uma vez que se encarrega da análise dos signos na sociedade, por meio de estudos sobre as trocas comunicativas que ocorrem dentro de um contexto social específico.

Kress e van Leeuwen (1998) desenvolveram uma teoria da multimodalidade resgatando ideias da Linguística Sistêmico-funcional que, ao se cruzar com a Semiótica Social, permite o enfoque multimodal em análises textuais, considerando, aqui, uma análise pensada na sintaxe visual. M. Halliday, principal expoente da Linguística Sistêmico-funcional, desenvolveu uma perspectiva de análise da linguagem que afirmava que as escolhas das pessoas, ao fazerem uso da língua, ocorrem em função de um contexto social.

Halliday (2004) entendia que a linguagem tinha propósitos sociais, os quais ele definiu como metafunções. O autor separou essas metafunções em Ideacional (constrói significados da nossa experiência com o mundo por meio de um sistema de significados representacionais), Interpessoal (expressa as interações e os papéis assumidos pelos participantes da troca comunicativa) e Textual (organiza a textualização por meio de um sistema). As três funções agiriam juntas e, enquanto a Ideacional e a Interpessoal

\footnotetext{
7 Todos os trechos traduzidos são de responsabilidade da autora deste artigo.
} 
representariam a manifestação da linguagem para o entendimento do ambiente e para a interferência sobre o outro, respectivamente, a Textual codificaria esses propósitos.

Kress e van Leeuwen (1998 e 2006) reelaboraram as metafunções de Halliday de forma a entender o potencial semiótico dos elementos que compõem um texto, considerando que esses elementos, responsáveis por materializar as funções, são visuais. Inicialmente, os autores chamaram a metafunção Ideacional de Representacional. À função Interpessoal, eles deram o nome de Interativa, visto que esta definiria como os recursos visuais constroem as relações entre os participantes da troca comunicativa. À função Textual de Halliday, eles deram o nome de Composicional. Esta última, na visão de Kress e van Leeuwen (2006), deve ser usada com o propósito de analisar as imagens que compõem o texto multimodal, fazendo referência aos significados obtidos por meio da distribuição dos elementos multimodais da imagem. É ela que servirá de base para a análise multimodal que propomos neste artigo.

Assim, a Sociossemiótica nos permite estudar os significados visualmente produzidos nos textos. Segundo Kress e van Leeuwen (1998), o texto escrito não é mais estruturado apenas por conectores verbais, mas visualmente, por meio de leiaute, blocos de textos, figuras e elementos gráficos que compõem a página. Além disso, esse tipo de estruturação aparece em todos os textos. "Jornais, revistas, relatórios de empresas, livros didáticos e vários outros tipos de textos não são mais apenas escritos, mas desenhados e articulados multimodalmente." (KRESS; VAN LEEUWEN, 1998, p. 187)

Aqui salientamos que, diferentemente do que se acreditava na semiótica tradicional, que via o signo como arbitrário, a Sociossemiótica entende os signos como motivados, visto que a cultura interfere nas representações. Consideramos essa motivação importante quando tratamos dos signos utilizados no jornalismo científico pois, neste gênero, as escolhas feitas pelo produtor do texto (o jornalista) possuem um objetivo claro e bem definido: divulgar a ciência para um público amplo e não especialista. Daí a constatação de que todas as escolhas feitas pelo jornalista ao produzir seu texto por meio do uso de recursos modais diversos são motivadas e intencionais. "Os produtores de signos usam as formas que eles consideram adequadas para a expressão dos significados, em qualquer meio onde eles possam produzir signos." (KRESS; VAN LEEWUEN, 2006, p. 8) 
Os autores acrescentam que a escolha dos modos semióticos que integram um texto é guiada pelo contexto comunicativo. Em se tratando do jornalismo científico, isso fica mais claro à medida que

... a comunicação exige que os participantes façam as suas mensagens as mais inteligíveis possíveis em um contexto particular. Eles escolhem formas de expressão que acreditam ser mais transparentes para os outros participantes. Por outro lado, a comunicação acontece em estruturas sociais que são inevitavelmente marcadas por diferenças de poder e isso afeta o modo como cada participante entende a noção de máximo entendimento. (KRESS; VAN LEEUWEN, 2006, p. 13)

Vale salientarmos que, nos textos multimodais, os modos de representação verbal e visual não são equivalentes e não veiculam os mesmos significados. Além disso, a imbricação entre eles afeta a forma com que a mensagem é recebida pelo leitor.

\section{Uma análise multimodal}

A análise descritiva de caráter qualitativo que propomos neste artigo serve como ferramenta para exemplificar a hibridização de modos semióticos no jornalismo científico, além de apontar para a maneira como esta atua no sentido de tornar o discurso mais didático e de fácil entendimento. Para tal, observamos como os modos semióticos presentes no discurso do jornalismo científico se apresentam ao leitor da revista Pesquisa FAPESP, com base nas categorias explicitadas por Kress e van Leeuwen na obra Reading Images. The grammar of visual design ${ }^{8}$ (2006), que investiga a composição visual do texto multimodal. A escolha por essa revista ocorreu porque a Pesquisa Fapesp é o veículo jornalístico impresso da maior agência de fomento do Brasil, a Fundação de Amparo à Pesquisa do Estado de São Paulo (FAPESP). Criada na década de 1990, a revista tem como principal objetivo divulgar as pesquisas científicas que são feitas pelos pesquisadores que a agência de fomento paulista financia.

\footnotetext{
${ }^{8}$ A partir deste momento, vamos nos referir a tal obra como Gramática do Design Visual.
} 
Assim como Kress e van Leeuwen (2006), consideramos que o leiaute de um texto envolve três sistemas de significados. Esses sistemas agem juntos para estruturar o texto, transformando fotos, imagens, gráficos, tabelas, linhas e blocos de texto em um todo coeso.

Abaixo, explicitamos cada uma das categorias de análise propostas pelos autores.

\section{Valor da informação ${ }^{9}$}

Trata-se da composição da página da revista como um todo e do posicionamento dos elementos multimodais no texto, de forma que a posição em que ocupam pode significar maior ou menor destaque àquele elemento. As várias zonas imagéticas da página são importantes para o significado que se quer alcançar. "Um elemento não tem o mesmo valor e o mesmo significado quando é posicionado à direita ou à esquerda, acima ou abaixo, no centro ou na margem da página. Cada uma dessas zonas agrega certo valor aos elementos que são colocadas nela." (KRESS; VAN LEEWUEN, 1998, p. 188)

Segundo a Gramática do Design Visual (2006), os elementos posicionados à esquerda são considerados como elementos Dados e, os elementos posicionados à direita, como elementos Novos $^{10}$. Os elementos Dados são aqueles que o leitor do texto, em tese, já conhece. Eles são familiares e servem como ponto de partida para a leitura do texto. Assim, à esquerda da página encontram-se as informações que são parte da cultura do leitor ou da cultura da revista. Já os elementos à direita da página são aqueles desconhecidos pelo leitor, que the causam algum estranhamento ou surpresa. Neste setor da página, são colocados elementos que o leitor deve prestar mais atenção para entender o texto.

Ainda na categoria de Valor da informação, temos a diferenciação entre Real e Ideal, categorias relacionadas à disposição dos elementos na parte superior ou inferior da página. $\mathrm{Na}$ parte superior, estão os elementos posicionados como Ideais. Estes fazem referência àquilo que é apresentado como idealizado ou genérico na informação. Esta é, também, a parte mais saliente da página, que chama mais a atenção do leitor. Já os elementos Reais, localizados na parte inferior da página, transmitem a informação mais específica e detalhada

\footnotetext{
${ }^{9}$ Em Kress e van Leewuen (1998 e 2006), tal categoria é chamada de Information value.

10 Tais categorias são chamadas de Given e New nas obras de Kress e Van Leeuwen.
} 
sobre o assunto que é abordado no texto. Trata-se daquilo que é útil para que o leitor consiga atribuir significado ao texto multimodal que lê. Quando observamos textos na parte superior da página e fotos na parte inferior, pode-se concluir que, neste caso, o texto exerce papel principal no texto multimodal em questão. Quando ocorre o contrário, a parte mais importante do texto multimodal é comunicada via imagens e o texto escrito funciona como suporte.

A terceira análise realizada na categoria Valor da informação faz referência à disposição dos elementos no centro e nas margens da página. Segundo Kress e Van Leeuwen (1998), tal organização de elementos multimodais é pouco comum no ocidente (onde prevalece a disposição que considera esquerda, direita, acima e abaixo). No caso do leiaute que usa a disposição por Centro, colocando um elemento em destaque no meio da página e os outros ao seu redor, o elemento que é posicionado neste centro é tido como o núcleo da informação, enquanto os elementos colocados à margem do texto são dependentes deste elemento principal.

Tal análise é resumida na figura abaixo, reproduzida da obra de Kress e Van Leeuwen (2006).

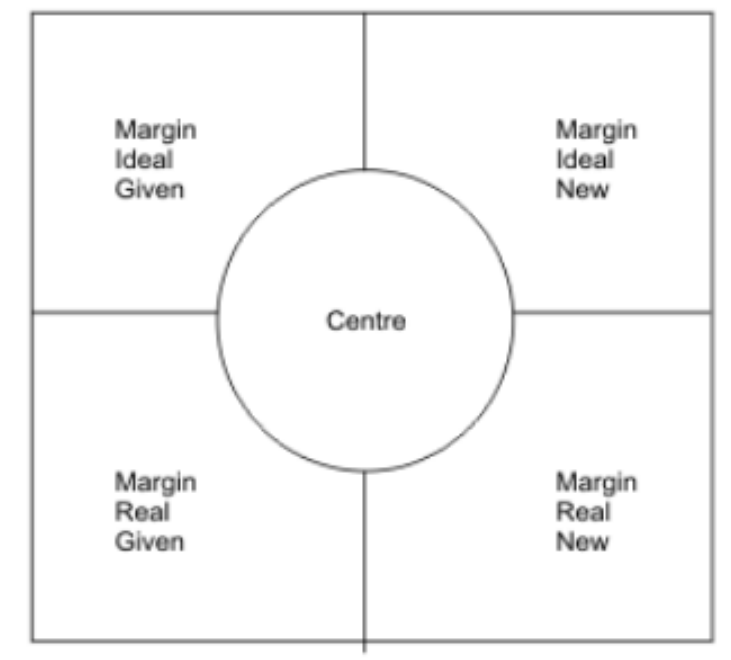

Figura 1. Valor dos modos semióticos de acordo com seu posicionamento na página Fonte: KRESS; VAN LEUWEEN, 2006, p. 197. 


\section{Saliência ${ }^{11}$}

A segunda categoria de análise que vamos considerar é a Saliência. Esta faz referência aos elementos que ganham destaque e estão mais salientes na página observada, atraindo a atenção do leitor. Uma vez que a categoria de Valor da informação permite a análise de onde os elementos da página devem ser posicionados e como esse posicionamento agrega valor ao texto multimodal, a composição da página também envolve diferentes graus de saliência e de destaque. A Saliência pode hierarquizar os elementos, não importando onde eles estejam posicionados.

Para Kress e van Leeuwen (1998), o leiaute de uma página é textual. Sendo assim, o posicionamento dos modos semióticos gera coerência na página e permite uma organização por ordem de importância.

... o leiaute também envolve o estabelecimento dos degraus de saliência dos elementos na página. Independentemente de onde eles são colocados, a saliência pode criar uma hierarquia de importância entre os elementos, selecionando alguns como mais importantes e mais merecedores de atenção imediata que outros. (KRESS; VAN LEEUWEN, 1998, p. 200)

Quanto maior o tamanho de um elemento na página, maior a sua saliência e a sua importância para o entendimento do texto. Além do tamanho do elemento, também contribuem para a saliência o seu brilho, a sua cor e a sua textura. Um texto que é colocado entre bordas escuras é mais saliente que um texto colocado sem bordas; imagens vermelhas e azuis são mais salientes que imagens em tons claros; objetos colocados em primeiro plano são mais salientes que objetos colocados em segundo plano; elementos que se sobrepõem a outros também são mais salientes que os elementos que são sobrepostos a eles. Além disso, elementos culturais e pessoas famosas também são elementos que agem no sentido de criar saliência no texto.

Segundo Kress e van Leeuwen (1998), ser capaz de observar as diferentes saliências dos elementos que integram um texto multimodal é ser capaz de entender como esses elementos atuam juntos para tornar o texto equilibrado. Sem esse balanço, a coordenação do

\footnotetext{
${ }^{11}$ Chamada por Kress e van Leewuen (1998 e 2006) de Salience.
} 
espaço da página seria impossível. Assim, o balanço que é ocasionado pelo modo como a saliência é usada no texto multimodal "forma uma matriz indispensável para a produção e recepção de mensagens organizadas espacialmente, e por essa razão ele também desempenha um papel importante na produção de um leiaute esteticamente prazeroso e, consequentemente, nossa relação afetiva com ele." (KRESS; VAN LEEUWEN, 1998, p. 201)

\section{Enquadramento ${ }^{12}$}

A terceira categoria de análise que utilizaremos em nosso artigo refere-se ao modo como os elementos da página estão conectados ou desconectados. Segundo Kress e van Leeuwen (1998),

... elementos podem estar fortemente ou fracamente enquadrados, e quanto mais fraco for o enquadramento, mais elementos em diferentes enquadramentos são apresentados como unidades separadas de informação. [...] Elementos também podem estar mais fortemente conectados e, quanto mais forte for essa conexão, mais eles serão apresentados como uma unidade de informação, como pertencendo ao mesmo grupo. (KRESS; VAN LEEUWEN, 1998, p. 203)

A continuidade e descontinuidade proporcionada pelo enquadramento pode ocorrer por meio do uso de linhas, cores e até mesmo pelo espaço em branco que é colocado entre os modos semióticos.

Após explicitarmos as categorias de análise que vamos utilizar, tomemos como objetos de observação três matérias jornalísticas publicadas na revista Pesquisa FAPESP de abril de 2018, ano 19, número 266. Partimos da matéria jornalística intitulada "Corações trocados", que trata do cinquentenário do primeiro transplante cardíaco ocorrido no Brasil.

\footnotetext{
12 Tradução para Framing, como a categoria é chamada por Kress e van Leeuwen.
} 


\section{CARDIOLOGIA 4 \\ Corações TROCADOS}

\author{
Cinquenta anos depois do \\ primeiro transplante cardíaco, \\ a sobrevida aumentou, \\ mas ainda faltam doadores
}

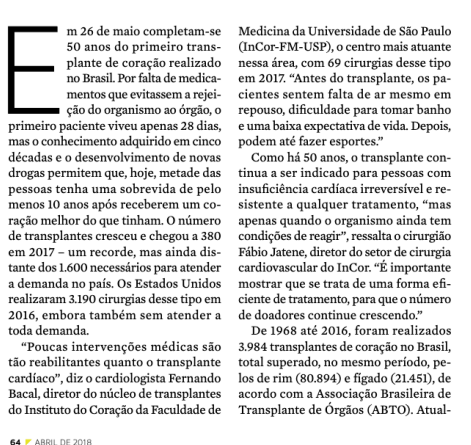

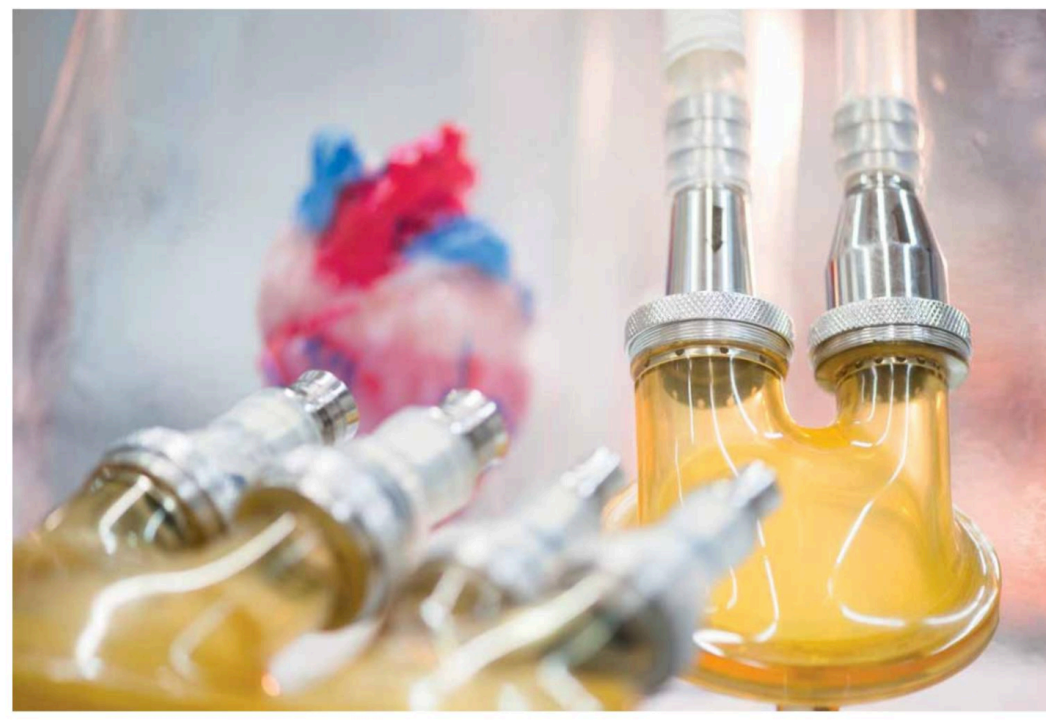

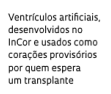

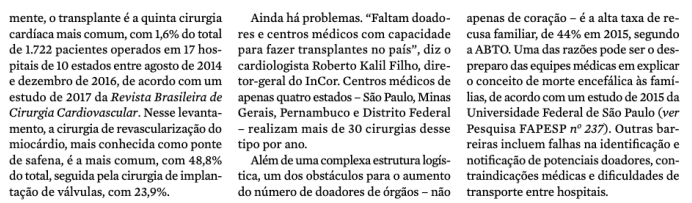

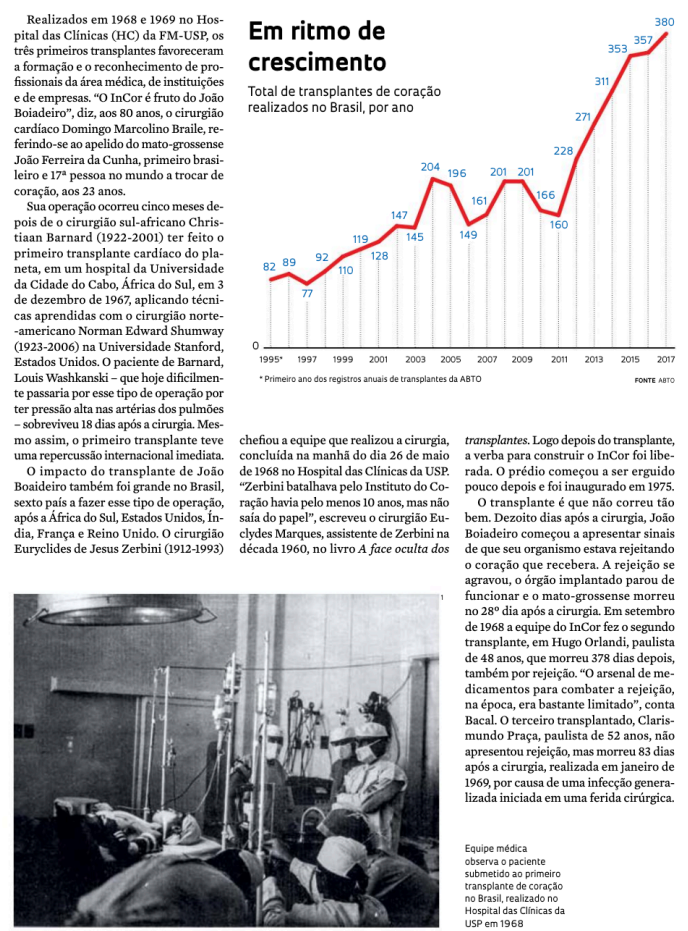

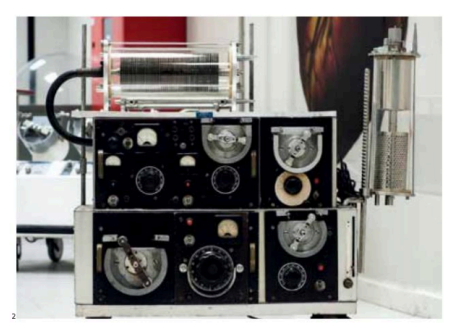

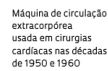

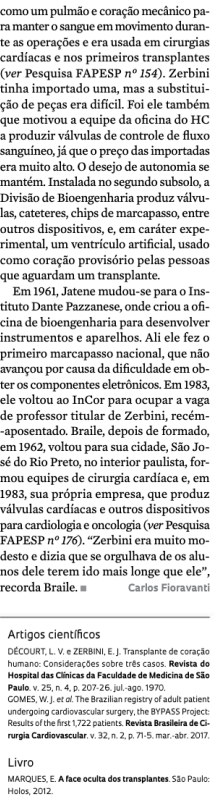

Figuras 2 e 3 . Reprodução das páginas da revista Fonte: Pesquisa FAPESP, 2018, p. 64-67. 
A matéria conta com duas páginas duplas e, logo em um primeiro olhar, já é possível observar a presença de mais de um tipo modal no texto. Na primeira página dupla, uma foto ocupa grande espaço no quadrante superior direito. O título "Corações trocados" produz efeito de sentido ao retomar um discurso poético e está posicionado no quadrante superior esquerdo, de certa forma distante do texto da matéria. No lado esquerdo da página, observam-se, ainda, muitos espaços brancos compondo a diagramação: tal recurso deixa o texto mais leve, tornando a leitura menos cansativa. Aqui, nota-se que o elemento considerado mais importante é a foto de ventrículos artificiais desenvolvidos no Instituto do Coração (InCor), que recebe destaque e encontra-se em saliência.

A mesma foto pode ser considerada como elemento Ideal e Novo. Acreditamos que poucas pessoas já viram um ventrículo artificial e seriam capazes de reconhecer este coração provisório que é usado por pacientes que aguardam o transplante. Sendo assim, trata-se de algo desconhecido pelo leitor, mas que ele deve prestar atenção para o entendimento do assunto que é tratado na matéria jornalística. Ainda nesta página, a parte inferior, dominada por texto, apresenta informações específicas e detalhadas sobre o transplante de coração no Brasil, como números e estatísticas da cirurgia no país, funcionando, assim, como elemento Real, como define a Gramática do Design Visual (2006).

Nas página dupla seguinte, que é a sequência da matéria jornalística, há menos espaços em branco na diagramação dos textos e apenas três elementos imagéticos. Inicialmente, vemos um gráfico e uma foto no meio da parte superior da página dupla considerada. Na parte inferior, vemos uma foto no canto esquerdo e uma grande concentração de texto escrito no lado direito. A foto está em preto e branco, o que materializa o passado, contrastando a imagem com a ideia de "presente" que é trazida pela inovação dos transplantes cardíacos. Nesta página, o setor denominado de Real é quase todo ocupado pela escrita. Neste caso, o excesso de texto escrito conta com informações mais específicas e detalhadas sobre o transplante de coração no Brasil.

Ainda na segunda página dupla da matéria jornalística, podemos observar, na categoria de enquadramento, uma linha que separa a matéria jornalística de uma ficha informativa com dados de artigos científicos e um livro que tratam do mesmo tema retratado na matéria. Aqui, esta linha tem a função de separar um texto que não integra o conteúdo da 
matéria jornalística, mas que pode ser interessante para quem deseja saber mais sobre o tema (a ficha com a indicação dos artigos científicos e do livro traz outras informações sobre o assunto, mas não é essencial para o entendimento do texto, como se constituísse uma espécie de "adendo" à matéria jornalística).

A presença do gráfico "Em ritmo de crescimento", também nesta segunda página dupla, exerce uma função didática no texto. Para mostrar ao leitor como se deu o ritmo de crescimento do número de transplantes realizados no país, foi utilizado o recurso do gráfico em reta. Tal gráfico explica o crescimento dos transplantes de uma forma que, talvez, o uso de texto escrito não seria capaz. As fotos da segunda página dupla ilustram o que o texto afirma: a primeira mostra uma máquina usada em cirurgias e, a segunda, a equipe médica que trabalhou no primeiro transplante de coração feito no Brasil.

Na matéria "Corações trocados", percebe-se que a junção de texto, imagens, gráficos e outros elementos é responsável por tornar o texto mais simples de ser entendido pelo leitor da revista Pesquisa FAPESP. O mesmo ocorre nas matérias jornalísticas "Quanto menor, melhor" e "Salto para o desconhecido", presentes na mesma edição. Na primeira, trata-se de uma matéria em página dupla que aborda o uso de nanopartículas para diminuir os agroquímicos das plantações. A segunda conta a história de uma empresa farmacêutica líder no seguimento de medicamentos genéricos. 

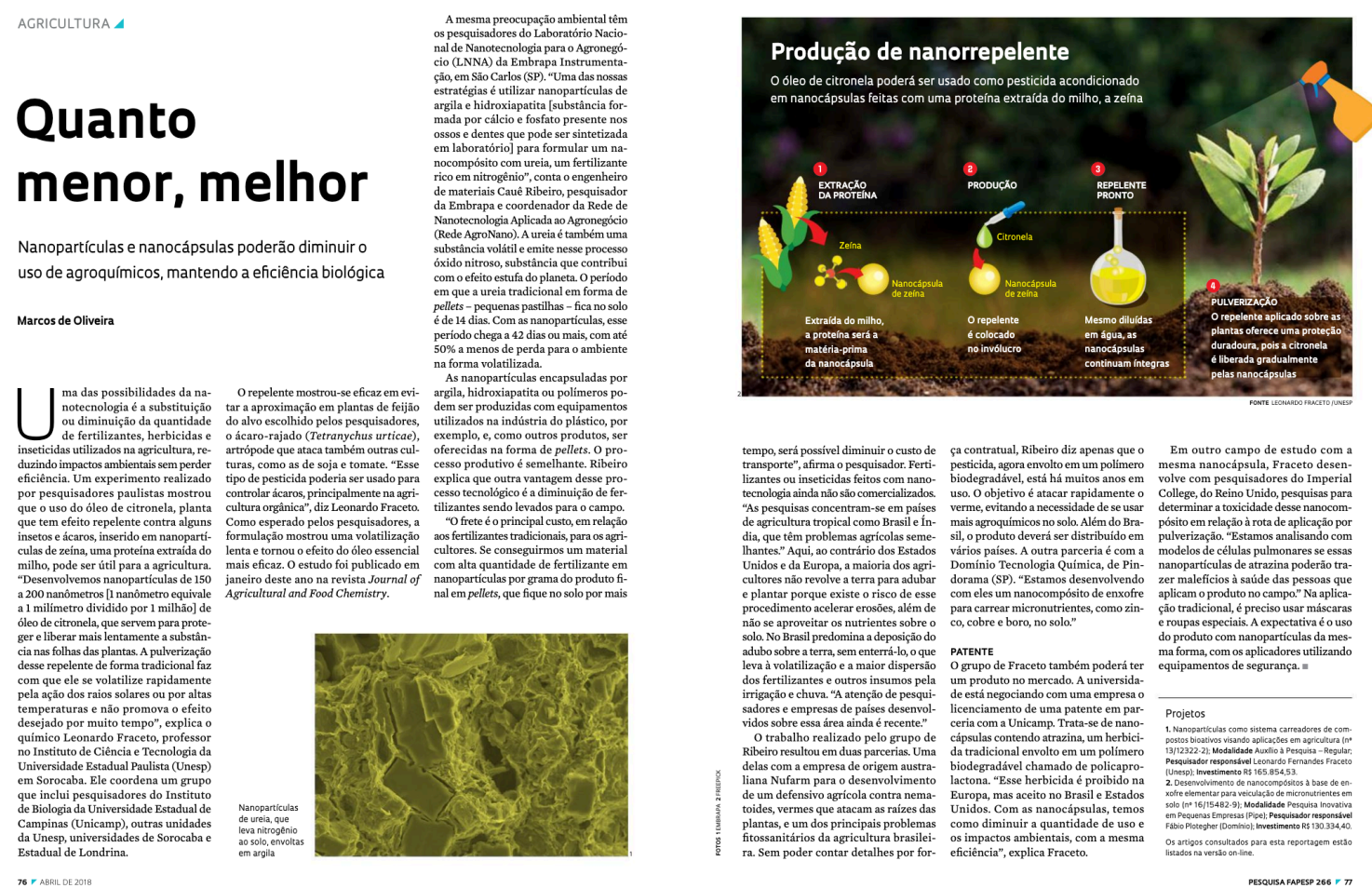

\section{PESQUISA EMPRESARIAL \\ Salto para o desconhecido}

Líder no segmento de genéricos, a farmacêutica EMS investe em inovação radical

Suzel Tunes
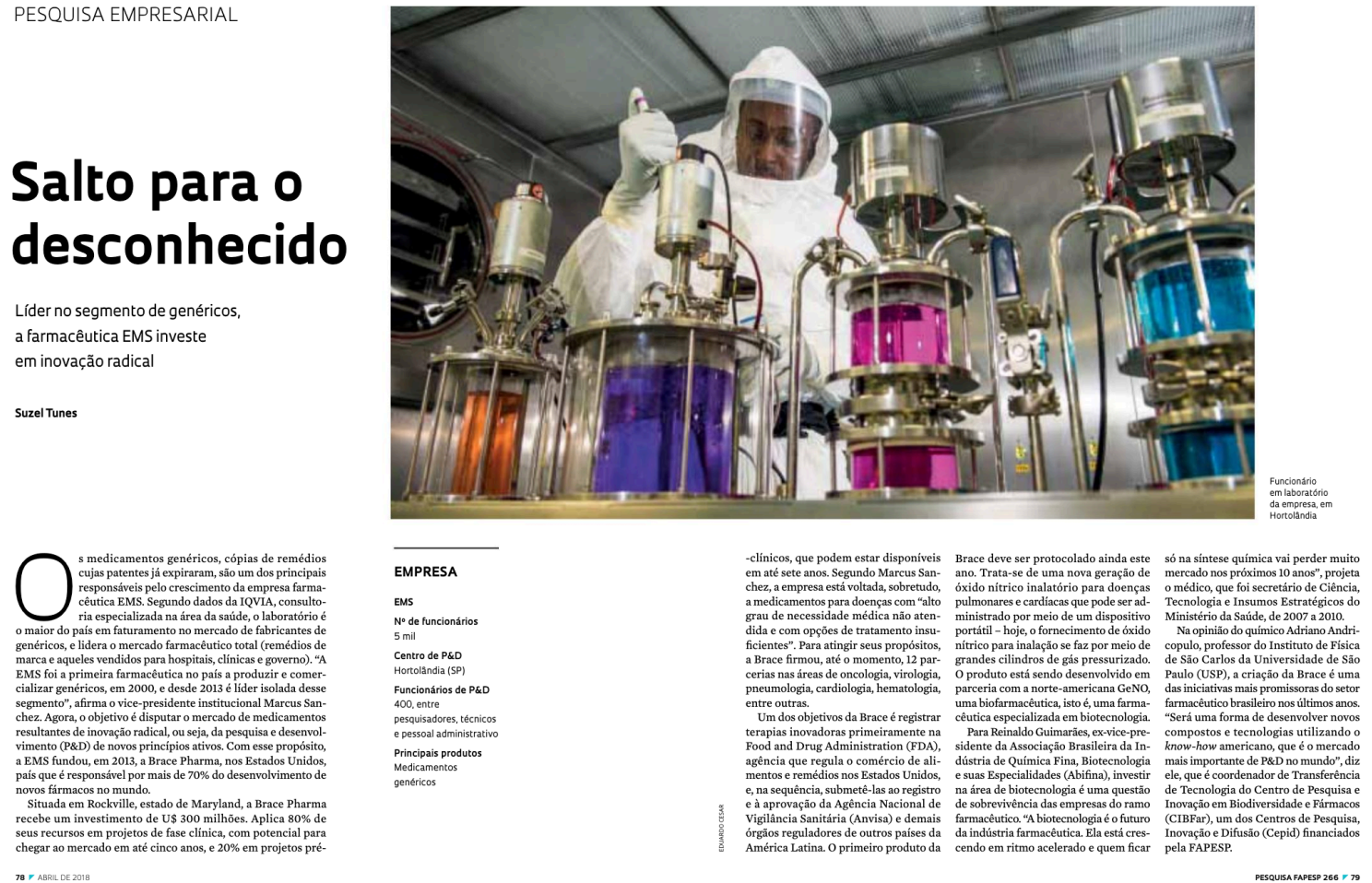

Figuras 3 e 4 . Reprodução das páginas da revista

Fonte: Pesquisa FAPESP, 2018, p. 76-89. 

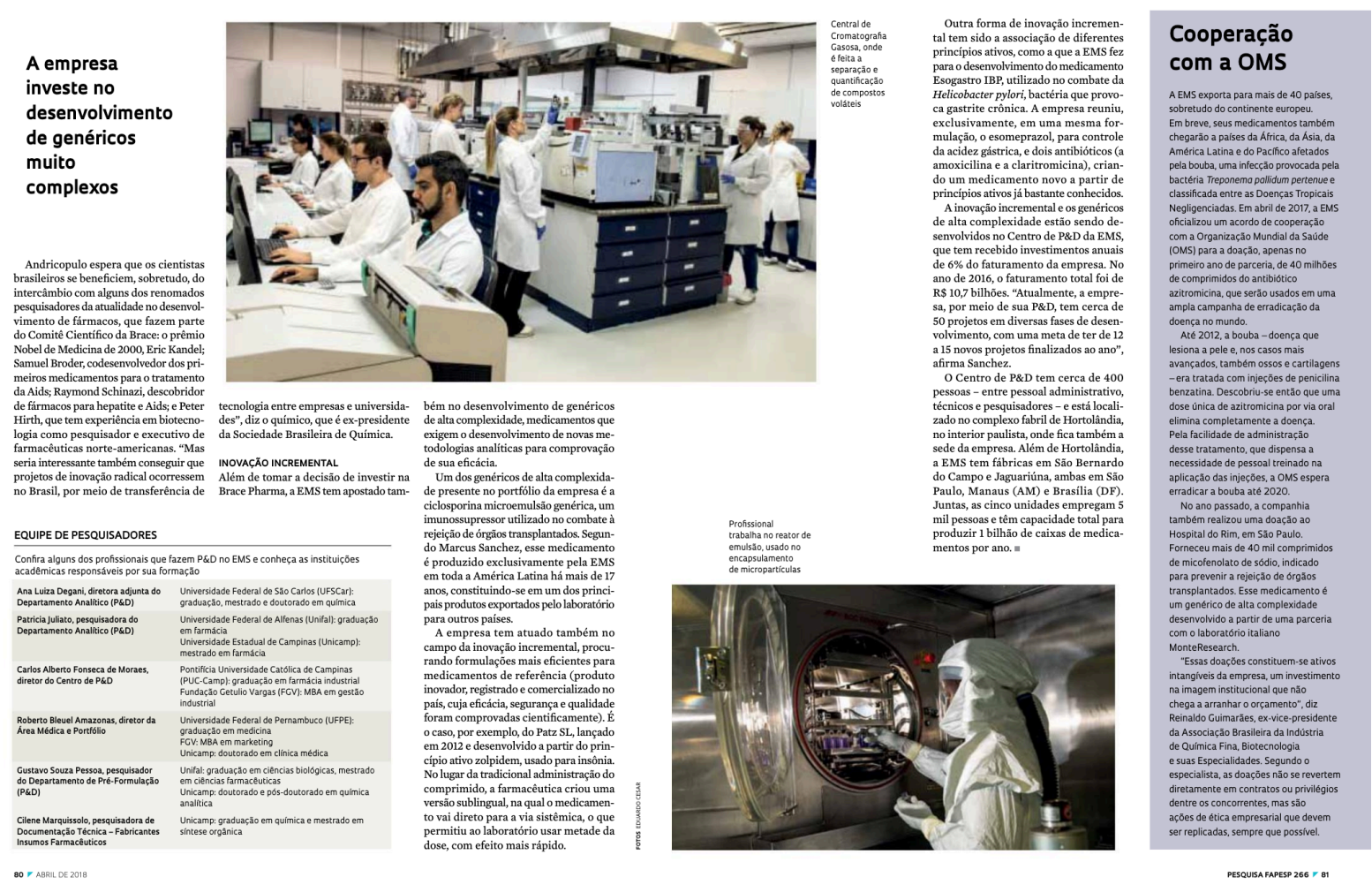

Figura 5. Reprodução das páginas da revista Fonte: Pesquisa FAPESP, 2018, p. 80-81.

Na matéria sobre as nanopartículas, no canto superior direito da página dupla, setor responsável pela informação mais genérica e saliente, encontra-se um infográfico que explica, por meio de desenhos e de forma bem didática, como ocorre a produção de nanorrepelente por meio do óleo de citronela. ${ }^{13}$ Os textos do infográfico são sucintos e as imagens são simples, de modo que o processo nanotecnológico (complexo de ser feito dentro dos laboratórios de pesquisa) se torna mais simples e inteligível para o público leigo da área. A posição do infográfico mostra, ainda, que este foi utilizado na página dupla como um elemento modal Novo, pois trata-se de uma informação desconhecida do leitor, mas importante para que ele consiga entender o conteúdo da matéria jornalística.

No canto inferior direito da matéria "Quanto menor, melhor", nos deparamos, mais uma vez, com uma linha que separa as informações sobre os projetos que realizam pesquisas

\footnotetext{
${ }^{13}$ O infográfico explica que o óleo de citronela pode ser usado como pesticida se acondicionado em nanocápsulas feitas de zeína, uma proteina extraída do milho.
} 
na área de nanotecnologia agrícola. Trata-se, aqui, de um elemento Real com informações específicas que complementam o texto mas que, uma vez separadas pelo fio da diagramação e apresentadas em fonte de tamanho menor que o restante da matéria jornalística, não são cruciais para o seu entendimento (tais informações podem ser ignoradas pelo leitor).

Apresentada com duas páginas duplas, a matéria "Salto para o desconhecido" também apresenta elementos modais diversos, com destaque para dois elementos que ainda não apareceram em nossas análises prévias. Na segunda página dupla, no canto lateral direito, ocupando os quadrantes inferior e superior da página, temos um quadro rosa com um texto que mostra a relação da empresa farmacêutica em questão com a Organização Mundial da Saúde (OMS). Trata-se de um elemento em saliência, uma vez que o recurso de cor foi capaz de destacá-lo, independentemente da posição que este ocupa nos quadrantes da página.

Ainda nesta página dupla vemos, no quadrante inferior esquerdo, uma espécie de tabela que lista os profissionais que trabalham no laboratório e suas respectivas formações. A tabela apresenta a lista dos profissionais de forma simples e organizada, separando esses dados do restante do texto que compõe a matéria. Percebe-se que a tabela é separada das colunas de texto da matéria por espaços em branco possibilitados pela diagramação da página, o que nos remete ao fato de que as informações contidas nesta tabela são interessantes, mas não são cruciais para o entendimento do assunto geral tratado na reportagem. Neste caso, a tabela é utilizada como estratégia de direcionamento do olhar do leitor.

\section{Considerações finais}

No mundo pós-moderno, os textos jornalísticos são constituídos por meio do entrelaçamento de palavras, cores e imagens, o que reflete o ritmo acelerado da vida das pessoas, que não têm tempo a perder e buscam ser informadas rapidamente. No caso específico do jornalismo científico, percebe-se que este gênero lança mão dos recursos multimodais para tornar o texto mais simples e inteligível ao público, uma vez que este campo do jornalismo lida com temas considerados complexos e com os quais as a maioria das pessoas tem pouco contato e/ou conhecimento. Além disso, a multimodalidade também 
possibilita a validação do dizer, ou seja, contribui para que seja alcançada uma noção de verdade e de credibilidade na informação.

Acreditamos que as articulações multimodais são fundamentais e precisam ser compreendidas e estudadas por pesquisadores do campo da Linguística Aplicada e dos estudos do discurso. Podemos dizer que a linguagem atual privilegia modalidades diferentes da escrita e que um enfoque apenas nesta modalidade não é capaz de revelar a totalidade dos fenômenos que envolvem o uso da língua. Concordamos com Ferraz (2008), quando esta afirma que "examinar a multimodalidade como característica constitutiva do texto é prerrogativa para elucidação das maneiras como as formas simbólicas são lidas e compreendidas por quem as produz e as recebe no seu decurso da vida." (FERRAZ, 2008, p. 7)

Quando falamos de multimodalidade, fazemos referência aos diversos modos semióticos do discurso, como o texto, as imagens, os gráficos, as tabelas, a diagramação etc. Acreditamos que a observação da maneira como esses elementos se fazem presentes na revista de jornalismo científico Pesquisa FAPESP foi capaz de exemplificar que o uso de recursos multimodais diversos pode facilitar o entendimento dos discursos, ajudando na compreensão de temas complexos e de pouca circulação na mídia brasileira.

Ao se preocupar com a inteligibilidade dos seus textos, este campo do jornalismo permite que discursos que costumam ficar restritos a um pequeno grupo de pessoas se tornem acessíveis a uma maior parcela da população. O discurso científico não deve ser utilizado como ferramenta de exclusão e exercício de poder pelo grupo que o produz, uma vez que este discurso é capaz de produzir conhecimento e contribuir para o aprendizado das pessoas.

Acreditamos que as boas práticas do jornalismo científico configuram atos de resistência necessários em uma sociedade que é cada vez mais descrente dos saberes científicos.

\section{Referências}

AUTHIER-REVUZ, J. Palavras incertas: as não-coincidências do dizer. Campinas: Unicamp, 1998.

BERTOLLI FILHO, C. Elementos para a prática do jornalismo científico. Disponível em: http://www.bocc.ubi.pt/_esp/autor.php?codautor=939. Acesso: em abr. 2018. 
BUENO, W. da C. Comunicação científica e divulgação científica: aproximações e rupturas. Inf. Inf., Londrina, v. 15, n. Esp, p. 1-12, 2010. Doi: https://doi.org/10.5433/19818920.2010v15nesp.p1.

FAIRCLOUGH, N. Language and power. Essex: Pearson Education , 2001.

FERRAZ, J. A. Gêneros multimodais: novos caminhos discursivos. In: Anais do VIII Encontro Nacional de Interação em Linguagem Verbal e Não Verbal. São Paulo: FFLCH-USP, 2008.

FIORAVANTI, C. Corações trocados. Pesquisa FAPESP, São Paulo, ano 19, n. 266, p. 64-67, abr. 2018.

FOLHA DE S. PAULO. Manual de redação. São Paulo: PubliFolha, 2001.

FOUCAULT, M. A ordem do discurso. Aula inaugural no College de France. Pronunciada em 2 de dezembro de 1970. Trad. de Laura Fraga de Almeida Sampaio. São Paulo: Loyola, 1996.

GNERRE, M. Linguagem, escrita e poder. São Paulo: Martins Fontes, 2009.

HALLIDAY, M. A. K. The language of science. London: Continuum, 2004.

HALLIDAY, M. A. K.; MATTHIESSEN, C. M. I. M. An introduction to functional grammar. London: Hodder Education, 2004.

HALLIDAY, M. A. K.; MARTIN, J. R. Writing science. Literacy and discursive power. London: The Falmer Press, 1996.

HODDGE, R.; KRESS, G. Social semiotics. Cambridge: Polity Press, 1988.

KRESS, G. Gain and losses: new forms of texts, knowledge and learning. Computers and composition, v. 22, p. 5-22, 2005. Doi: https://doi.org/10.1016/j.compcom.2004.12.004.

KRESS, G. Against arbitrariness: the social production of the sigh as a foundational issue in critical discourse analysis. Discourse and society, v. 4, n. 2, p. 169-91, 1993. Doi: https://doi.org/10.1177/0957926593004002003.

KRESS, G. Multimodality. A social semiotic approach to contemporary communication. London: Routledge, 2010. Doi: https://doi.org/10.4324/9780203970034.

KRESS, G. Multimodal discourse analysis. In: GEE, J. P; HANDFORD, M. (Org.). The Routledge handbook of discourse analysis. London: Routledge, 2012. p. 33-50.

KRESS, G.; VAN LEEUWEN, T. Reading images: the grammar of visual design. London: Routledge, 2006. Doi: https://doi.org/10.4324/9780203619728.

KRESS, G.; VAN LEEUWEN, T. Colour as a semiotic mode: notes for a grammar of colour. Visual Communication, $\quad$ v. 1 , n. 3, p. 343-368, $2002 . \quad$ Doi: https://doi.org/10.1177/147035720200100306 
KRESS, G.; VAN LEEUWEN, T. Multimodal discourse. The modes of contemporary communication. London: Oxford University Press, 2001.

KRESS, G; VAN LEEUWEN, T. Front pages: (The critical) analysis of newspaper layout. In: BELL, A.; GARRETT, P. (Org.) Approaches to media discourse. Hoboken: Blackwell Publishing, 1998. p. 186-219.

KRESS, G.; VAN LEEUWEN, T. Multimodal discourse: the modes and media of contemporary communication. London: Arnold, 2001.

OLIVEIRA, F. de. Jornalismo científico. São Paulo: Ed. Contexto, 2002.

OLIVEIRA, M. de. Quanto menor, melhor. Pesquisa FAPESP, São Paulo, ano 19, n. 266, p. 7677, abr. 2018.

PESQUISA FAPESP. Edição de agosto de 2018, ano 19, no 270.

ROJO, R. Textos Multimodais. In: FRADE, I.C.A.S.; COSTA VAL, M.G.; BREGUNCI, M.G.C. (Org.). Glossário Ceale. Disponível em: http://www.ceale.fae.ufmg.br/app/webroot/glossarioceale/verbetes/textosmultimodais/; acesso em: jun. 2018.

SOUSA, J. P. Elementos de jornalismo impresso. Florianópolis: Letras contemporâneas Oficina Editorial, 2005.

TUNES, S. Salto para o desconhecido. Pesquisa FAPESP, São Paulo, ano 19, n. 266, p. 78-81, abril de 2018. 